\title{
Nest ectoparasites increase physiological stress in breeding birds: an experiment
}

\author{
Josué Martínez-de la Puente \& Santiago Merino \& \\ Gustavo Tomás \& Juan Moreno \& Judith Morales \& \\ Elisa Lobato \& Javier Martínez
}

\begin{abstract}
Parasites are undoubtedly a biotic factor that produces stress. Heat shock proteins (HSPs) are important molecules buffering cellular damage under adverse conditions. During the breeding season, blue tit Cyanistes caeruleus (L.) adults are affected by blood parasites, nest-
\end{abstract}

J. Martínez-de la Puente ‘ S. Merino · J. Moreno

Departamento de Ecología Evolutiva,

Museo Nacional de Ciencias Naturales (CSIC),

J. Gutiérrez Abascal 2,

28006, Madrid, Spain

G. Tomás

Departamento de Ecología Funcional y Evolutiva, Estación Experimental de Zonas Áridas (C.S.I.C.), Carretera de Sacramento s/n, La Cañada de San Urbano,

04120, Almería, Spain

\section{J. Morales}

Departamento de Ecoloxía e Bioloxía Animal, Facultade de Biología, Universidade de Vigo, Vigo 36310, Spain

\section{E. Lobato}

Centre d'Ecologie Fonctionelle et Evolutive, CNRS,

1919 Route de Mende,

Montpellier, France

\section{J. Martínez}

Departamento de Microbiología y Parasitología,

Facultad de Farmacia, Universidad de Alcalá,

Alcalá de Henares,

28871, Madrid, Spain

Present Address:

J. Martínez-de la Puente ( $\star$ )

Department of Animal Science, Universidad de Las Palmas de

Gran Canaria,

Las Palmas de Gran Canaria,

35416, Arucas, Spain

e-mail: jmartinez@becarios.ulpgc.es dwelling parasites and biting flies, potentially affecting their HSP-mediated responses. Here, we treated females with primaquine to reduce blood parasites and fumigated nests with permethrin to reduce nest-dwelling parasites to test whether these treatments affect HSP60 level during the breeding season. Medicated females, but not controls, had a significant reduction of the intensity of infection by Haemoproteus spp. blood parasites. However, final intensity of infection did not differ significantly between groups, and we did not find an effect of medication on change in HSP60 level. Fumigation reduced the abundance of nestdwelling parasites (mites, fleas and blowfly larvae) and engorged biting midges in nests. Females breeding in nonfumigated nests increased HSP60 levels during the season more than those breeding in fumigated nests. Furthermore, the change in HSP60 level was positively correlated with the abundance of biting midges. These results show how infections by nest ectoparasites during the breeding period can increase the level of HSPs and suggest that biting midges impose physiological costs on breeding female blue tits. Although plausible, the alternative that biting midges prefer to feed on more stressed birds is poorly supported by previous studies.

Keywords Birds · Biting midge Culicoides · Parasitism • Physiological costs

Introduction

Parasites have a major impact on life history strategies of their hosts and have been proposed as an important ecological and evolutionary force (Atkinson and van Riper 1991; Møller 1997). Injuries produced by parasites may be reflected on host physiological mechanisms directed at 
surmounting infections. Buchanan (2000) defined a stress response as "physiological changes to short- or long-term unpredictable alterations in environmental circumstances, which cause a redirection of resources to vital processes and impair, or threaten to impair, homeostasis". Heat shock proteins (HSPs) are highly evolutionary conserved molecules buffering cellular damage under adverse situations. HSPs are intracellular proteins involved in cellular processes such as protein synthesis, protein degradation, stabilisation of microfilaments and regulation of immune responses (Feder and Hofmann 1999; Sørensen et al. 2003). HSP synthesis is induced by different environmental stimuli such as high and low temperatures, radiation, physical activity and toxins, including heavy metals and pesticides (Sørensen et al. 2003). Because parasites are one of the most widely distributed biotic inducers of stress for their hosts, they may induce HSP-mediated responses in animals (Merino et al. 1998a; Martínez et al. 1999; Rinehart et al. 2002).

During the reproductive season, birds suffer the attack of a diversity of parasites. HSPs may represent effective responses to infections by blood parasites and other endoparasites (Merino et al. 2002; Martínez-Padilla et al. 2004; Tomás et al. 2005; Arriero et al. 2008; del Cerro et al. 2010). Concretely, HSP60 mediates the costs of infection by martin bugs Oeciacus hirundinis (Lamarck) and blowfly larvae Protocalliphora spp. (Hough) in nestling house martins Delichon urbica (L.) and blue tits Cyanistes caeruleus, respectively (Merino et al. 1998a; Arriero et al. 2008). Also, injuries produced by the attack of nest-dwelling parasites and the increase in parental effort to reduce the cost of parasitism on nestlings may affect the stress response of adult females breeding in more intensely infested nests (de Lope and Møller 1993; de Lope et al. 1993; Merino et al. 1998b; Richner and Tripet 1999; Fitze et al. 2004; Tomás et al. 2007). Females may be especially vulnerable to parasitic attacks as they provide the majority of parental care. Therefore, breeding females may respond at a physiological level, in a similar way as nestlings do, by increasing their HSP60 levels in response to the effects of nest-dwelling parasites. However, this possibility should be tested because age is considered an important factor affecting the capacity of HSPs expression as well as stress tolerance (Feder and Hofmann 1999). In addition to nest-dwelling parasites, females also suffer the attack of biting flies during the incubation and brooding (Griffing et al. 2007; Tomás et al. 2008a; Ligon et al. 2009; Burkett-Cadena et al. 2010). Biting flies are blood feeders and vectors of pathogens (Kettle 1995; Lehane 2005), potentially imposing costs on adult females. However, information on the role of these insects in affecting avian physiological condition is scarce, especially for wild adult birds.

The aim of this study was to identify the role of both blood parasites and nest-dwelling parasites on the change in
HSP60 level throughout the breeding season in adult female blue tits. To this end, we performed a full factorial medication and fumigation experiment to reduce the abundance of blood parasites and nest-dwelling parasites, respectively. Based on a potential synergistic effect of different kinds of parasites on the stress response, we predict an increase in the change in HSP60 level in female birds more infected by blood parasites and breeding in nests infested by nest-dwelling parasites as the season progresses because populations of nest-dwelling parasites and therefore their effects on stress responses also increase with the advance of the season (see, for example, Merino and Potti 1995). A smaller increase in HSP60 is expected for females breeding in nests with reduced levels of nest-dwelling parasites or with reduced levels of blood parasites. The lowest level of increase in HSP60 is expected for female birds with reduced levels of both nest-dwelling parasites and blood parasites. Also, we test for the potential effect of biting flies on the change in female HSP60 level by quantifying biting midges Culicoides spp. (Latreille) in nests.

\section{Materials and methods}

This study was conducted during the spring of 2005 on a blue tit population breeding in nest-boxes in a Pyrenean oak Quercus pyrenaica (Willd.) deciduous forest in Valsaín, Central Spain (Segovia, 40 53' 74N, 401' W, $1200 \mathrm{~m}$ above sea level). Nests were periodically inspected to determine reproductive stage. Adults were captured twice using traps attached to nest-box entrances when nestlings were 3 and 13 days old. Nestling weight was measured at 13 days of nestling. The average of nestling body mass per brood was calculated.

\section{Treatments}

At first capture, nests were either assigned to a medication or control treatment and their nests were either assigned to a fumigation or control treatment (a $2 \times 2$ design). The medication treatment consisted in a subcutaneous injection of $0.1 \mathrm{ml}$ of the antimalarial drug Primaquine (Sigma, St Louis, MO, USA) diluted in saline solution (concentration $1 \mathrm{mg} \mathrm{ml}^{-1}$ ) to reduce infection by Haemoproteus spp. (Merino et al. 2000, 2004; Martínez-de la Puente et al. 2010b). Primaquine is an antimalarial compound effectively affecting gametocytes of several species of Plasmodium, including Plasmodium falciparum (López-Antuñano 1999; WHO 2001). Non-medicated females were injected with the same volume of saline solution. Fumigation was carried out at 3, 7 and 11 days of nestling age using the insecticide Stockade $\odot$ (Fort Dodge Veterinaria S.A., Vall de Bianya, 
Girona, Spain) comprising $0.5 \%$ permethrin and $1 \%$ piperonyl butoxide. This insecticide is ready to use by its application on the skin of dogs and cats and has been previously used in this population without negative effects on birds (Tomás et al. 2007; Lobato et al. 2008). To avoid any damage, nestlings were extracted from nests prior to fumigation and left again in the nest immediately after treatment. The same methods were employed in nonfumigated nests but spraying water instead of insecticide.

\section{Provisioning rate monitoring}

At first capture, females were uniquely identified with a micro-transponder (Trovan ID 103; length, $11.6 \mathrm{~mm}$; mass, $0.1 \mathrm{~g}$; Trovan Ltd., UK) glued to two colour rings on one leg to estimate provisioning rates to nestlings. On day 7 (hatching day $=0$ ) a data-logger (Trovan, EID Iberica, Madrid, Spain) connected to an antenna was attached to the nest-box entrance during an average $( \pm \mathrm{SD})$ of $2.35 \pm$ $1.51 \mathrm{~h}(\mathrm{n}=45)$ to obtain the number of feeding visits performed by each sex. Results express provisioning rates relative to 1 -h periods. The first 30 min were not included, to allow birds to get used to the presence of the data-logger (females provided their nests regularly after this period; pers. obs., see also Tripet et al. 2002). Transponders were removed from bird legs when birds were recaptured.

\section{HSP quantification}

At each capture, birds were blood-sampled through venipuncture of the brachial vein. Blood was collected in $85-\mu \mathrm{L}$ heparinised capillary tubes and immediately transferred to plastic vials with a lock and kept in a cool box with coldblocks until frozen. Temperature inside cool box does not exceed $15^{\circ} \mathrm{C}$. Later, blood samples were centrifuged in the field with a portable centrifuge and the plasma and cellular fractions were separated. These fractions were frozen on the same day of sampling at $-80^{\circ} \mathrm{C}$. Cell fractions were employed to quantify HSP60 using Western blot (Tomás et al. 2004). HSP60 levels are expressed in arbitrary units (optical density $\times$ area). The change in HPS60 level in the course of the breeding season was quantified as the difference between final minus initial levels.

\section{Blood sample collection}

To quantify the intensity of infection by Haemoproteus spp., a drop of blood from initial and final samples was immediately smeared on a microscopic slide and air-dried. Smears were later fixed in absolute ethanol and stained with Giemsa for $45 \mathrm{~min}$. Smears were scanned under light microscope at $\times 1,000$ magnification with oil immersion to search for blood parasites. The intensity of infection by
Haemoproteus spp. was calculated as the number of parasites per 2,000 erythrocytes (Merino et al. 2004). Although some females were found uninfected by microscopy examination of smears, all sampled females were included in analyses because of the extremely high prevalence of infection by Haemoproteus parasites in our population, as detected by molecular methods (see Martínez et al. 2009). We failed to obtain smears from one initial capture and one final capture of two different birds.

Biting fly collection and quantification

For 2 days after the last fumigation (days 12 and 13 of nestling age), we captured biting midges using the method described and tested by Tomás et al. (2008a). In brief, the method consists of placing a plastic Petri dish $(8.5 \mathrm{~cm}$ diameter; $56.7 \mathrm{~cm}^{2}$ ) with a thinly spread layer of commercially available body gel-oil where insects get trapped inside and close to the roof of each nest-box. On day 13, Petri dishes were removed and subsequently stored in a freezer until examination. We quantified the abundance of biting midges using an Olympus SZH stereomicroscope ( $\times 10$ to $\times 64$ magnification) as the number of flies per Petri dish captured during 2 days. Abundance of biting midges whose abdomens were engorged from blood meals was quantified (see Martínez-de la Puente et al. 2009). The abundance of biting midges was $\log _{10}(x+1)$ transformed to normalise its distribution. The presence of black flies in this study was reduced to one black fly per nest in three different nests, and therefore, these flies have not been considered in statistical analyses given their extremely low prevalences and abundances during this year.

Nest-dwelling parasite collection and quantification

On day 20 after hatching, when all nestlings had already fledged, nests were collected and nest-dwelling parasites extracted using Berlese funnels for $48 \mathrm{~h}$. The intensity of infection by mites Dermanyssus spp. and fleas Ceratophyllus gallinae (Schrank) was determined with the aid of a magnifying glass, under which the number of individuals of each type of arthropod was estimated as described in Merino and Potti (1995). Later, the nest material was teased apart over a white piece of paper to count the total number of pupae of blowflies Protocalliphora azurea (Fallen) (Merino and Potti 1995).

\section{Statistical analysis}

The change in HSP60 level was measured for 48 females breeding in nests where the abundance of biting midges was estimated. Sample size include 13 medicated females breeding in non-fumigated nests, 12 medicated females 
breeding in fumigated nests, 11 non-medicated females breeding in non-fumigated nests and 12 non-medicated females breeding in fumigated nests.

Statistical analyses were conducted using Statistica (version 6.0, StatSoft, Inc. 2001). ANOVA was used to test for the effect of the fumigation treatment on the abundance of total biting midges. The abundance of nest-dwelling parasites, the abundance of engorged biting midges and the intensity of infection by Haemoproteus spp. did not follow a normal distribution even after transformation. MannWhitney $U$ test was used to test for the effect of fumigation treatment on the abundance of nest-dwelling parasites and the abundance of engorged biting midges. Wilcoxon matched-pairs test was used to test for the effect of the medication treatment on the intensity of infection by Haemoproteus spp. To test for the effect of treatments on the change in HSP60 level (final minus initial levels), a two-way analysis of variance applying the forward stepwise solution was conducted including the change in HSP60 level as dependent variable, and the fumigation and medication treatments and their interaction as factors. Results were also confirmed using the backward stepwise solution. Despite some controversy, the use of stepwise modelling remains widespread in ecological and behavioural studies (Whittingham et al. 2006). We also used simple correlations to test for the effect of the abundance of each nest-dwelling parasites (mites, blowflies and fleas) and biting midges on the change in HSP60 level. Because provisioning rates did not follow a normal distribution, Kruskal-Wallis test was used to test for differences in this variable among experimental groups. Residuals of the parametric models were tested for normality.

\section{Results}

\section{Fumigation and medication treatment effects}

The fumigation treatment reduced nest-dwelling parasite abundances in nests (Fig. 1; Mann-Whitney $\mathrm{U}$ test; mites, $\mathrm{Z}$ adj=3.62, $\mathrm{p}<0.001$; blowflies, $\mathrm{Z}$ adj $=5.54, \mathrm{p}<0.001$; fleas, $\mathrm{Z}$ $\operatorname{adj}=2.79, p=0.005$ ). Although fumigation did not significantly reduce the number of biting midges (ANOVA, $\mathrm{F}_{1,46}=$ $3.15, p=0.08)$, it did reduce the number of engorged biting midges (Mann-Whitney $\mathrm{U}$ test, $\mathrm{Z}$ adj=2.74, $\mathrm{p}=0.006$ ).

Prior to medication treatment, there was no significant difference among levels of infection by Haemoproteus spp. in female blue tits subsequently medicated (Fig. 2; $\mathrm{N}=25$; mean \pm SD, $24.5 \pm 24.6$ ) or treated as controls (Fig. 2; $N=23$; mean \pm SD, 34.1 \pm 39.1$)$ (Mann-Whitney U test, $\mathrm{Z}$ adj $=0.61$, $\mathrm{p}=0.54$ ). Only four females included in this study were uninfected by Haemoproteus parasites at first capture as shown by microscopic examination of smears. Two of them

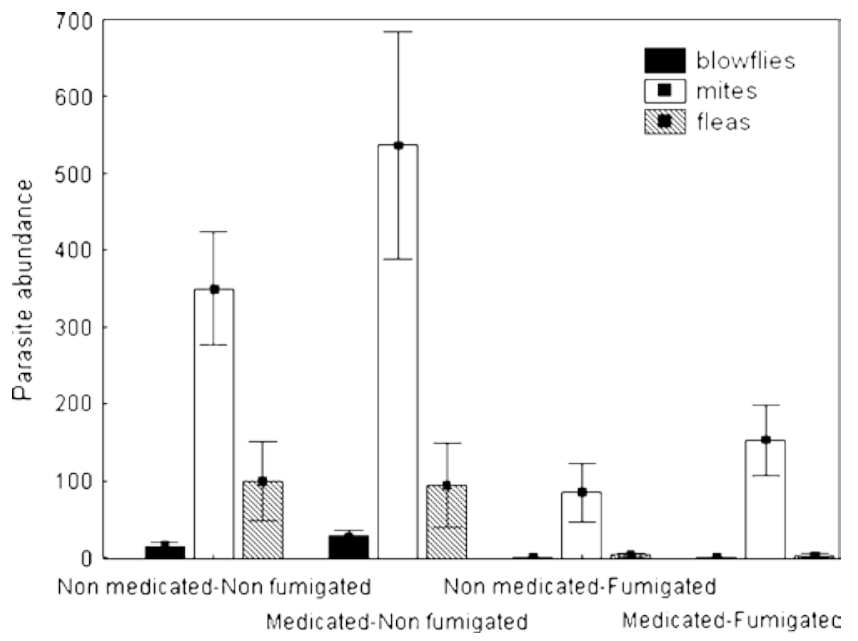

Fig. 1 Mean ( \pm SE) abundance of nest-dwelling ectoparasites in avian nests. Four groups were included in this study: non-medicated females breeding in non-fumigated nests, medicated females breeding in nonfumigated nests, non-medicated females breeding in fumigated nests and medicated females breeding in fumigated nests. The abundance of blowflies (filled bars), mites (empty bars) and fleas (hatched line bars) are shown

were medicated and bred in fumigated nests; one was medicated and bred in a non-fumigated nest and the other one was treated as control (non-medicated) and bred in a fumigated nest. Medicated females experienced a significant reduction in the intensity of infection by Haemoproteus spp. in the course of the season (final intensity of infection (mean $\pm S D$ ), 16.13 \pm 20.12 ; Wilcoxon matchedpairs test, $\mathrm{Z}=2.35, \mathrm{p}=0.02$ ), but not non-medicated females (final intensity of infection (mean \pm SD), 28.26 \pm 51.86 ; $\mathrm{Z}=$ $0.71, \mathrm{p}=0.48$ ). However, there was no significant difference in final Haemoproteus spp. infection intensity between treatments $(\mathrm{Z}$ adj $=-1.06, \mathrm{p}=0.29)$. Prior to treatment, brood

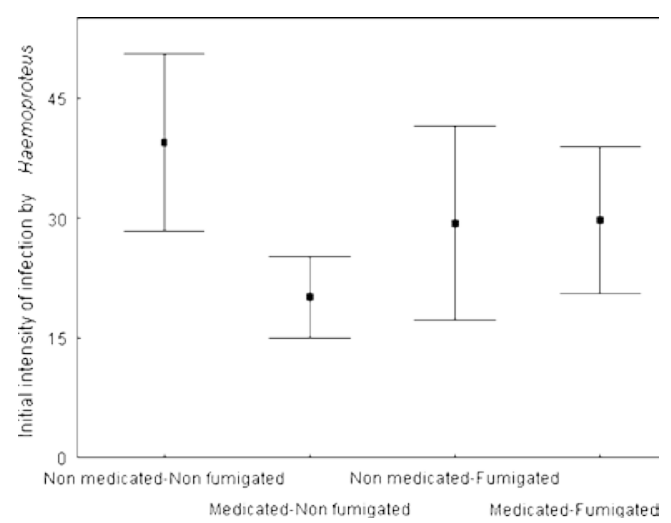

Fig. 2 Mean ( \pm SE) initial intensity of infection by Haemoproteus spp. parasites in female blue tits. Four groups were included in this study: non-medicated females breeding in non-fumigated nests, medicated females breeding in non-fumigated nests, non-medicated females breeding in fumigated nests and medicated females breeding in fumigated nests 
size did not differ among experimental groups (KruskalWallis test, $\mathrm{H}=2.74, \mathrm{p}=0.43, \mathrm{~N}=48$ ).

\section{HSP levels}

The initial level of HSP60 did not differ among females prior to treatment, and there was not a significant interaction between treatments (medication treatment, $\mathrm{F}_{1,44}=0.39, \mathrm{p}=0.54$; fumigation treatment, $\mathrm{F}_{1,44}=3.05, \mathrm{p}=$ 0.09 ; interaction, $\mathrm{F}_{1,44}=0.25, \mathrm{p}=0.62$ ). The fumigation treatment was the only variable retained $\left(\mathrm{F}_{1,46}=4.56, \mathrm{p}=\right.$ 0.038) in the model including the change in HSP60 level as dependent variable, and fumigation and medication treatments and their interaction as factors. That is, females attending non-fumigated nests increased their HSP60 level significantly more than females attending fumigated nests (Fig. 3). This result was further supported when initial and final levels of HSP60 were included in a repeated-measures ANOVA with fumigation treatment as a factor $\left(\mathrm{F}_{1,46}=4.56\right.$, $\mathrm{p}=0.038$ ). In addition, the change in female HSP60 level was significantly and positively associated with the abundance of biting midges (simple regression, $\mathrm{F}_{1,46}=7.72, \mathrm{p}<$ 0.01, Fig. 4). Further analyses revealed a significant association for females attending non-fumigated nests $\left(\mathrm{F}_{1,22}=5.76, \mathrm{p}=0.03\right)$ but not for those attending fumigated nests $\left(\mathrm{F}_{1,22}=1.20, \mathrm{p}=0.29\right)$. The change in female HSP60 level was not significantly correlated with the abundance of mites, flies or blowflies in both fumigated and nonfumigated nests (all $\mathrm{p}>0.13$ ).

Provisioning rates (mean \pm SD) were $9.1 \pm 5.3,11.6 \pm 5.2$, $12.2 \pm 8.6$ and $11.3 \pm 4.2$ for medicated females breeding in control and fumigated nests and control females breeding in control and fumigated nests, respectively. Female provisioning rates did not differ significantly among treatments (Kruskal-

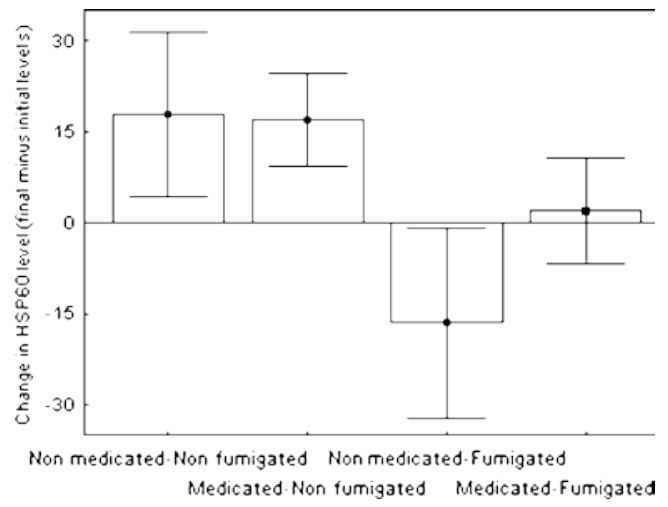

Fig. 3 Mean $( \pm$ SE) change in HSP60 level (final minus initial levels) of adult female blue tits for each treatment group. Four groups were included in this study: non-medicated females breeding in nonfumigated nests, medicated females breeding in non-fumigated nests, non-medicated females breeding in fumigated nests and medicated females breeding in fumigated nests. HSP60 levels are expressed in arbitrary units (optical density $\times$ area)

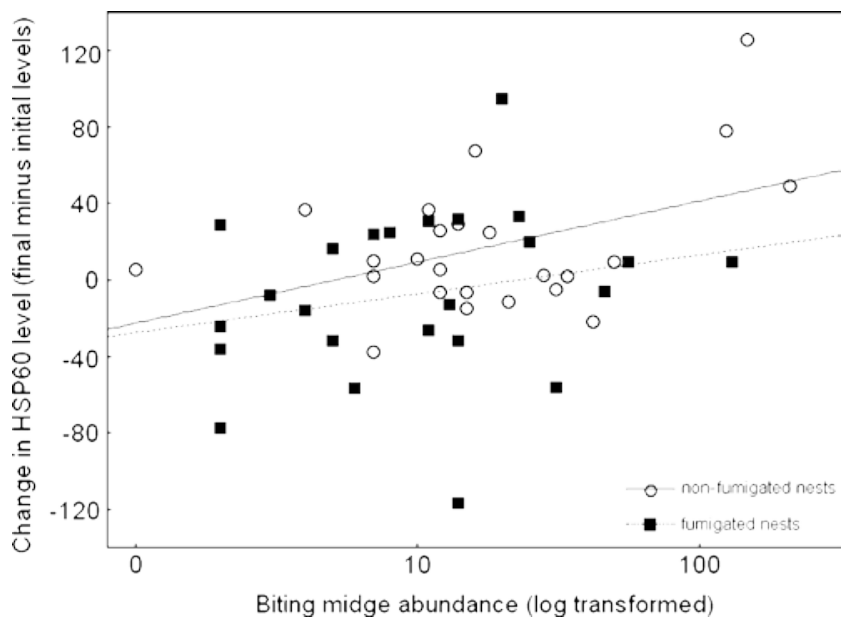

Fig. 4 Relationship between the change in female HSP60 level (final minus initial levels) and the total abundance of biting midges in fumigated (squares, dotted line) and non-fumigated (circles, continuous line) nests. The abundance of biting midges was log-transformed. HSP60 levels are expressed in arbitrary units (optical density×area)

Wallis test, $\mathrm{H}=1.41, \mathrm{p}=0.70, \mathrm{~N}=45$ ). The change in female HSP60 level was not significantly correlated with provisioning rates of females attending non-fumigated nests (Spearman correlation, $\left.R_{S}=0.27, p=0.21\right)$ or fumigated nests $\left(R_{S}=0.16\right.$, $\mathrm{p}=0.48$ ). We did not find any significant association between the change in HSP60 level and nestling weight within experimental groups (all $\mathrm{p}>0.37$ ). Neither nestling body mass nor nestling survival till 13 days of age differed significantly among experimental groups (all $\mathrm{p}>0.14$ ).

\section{Discussion}

During the breeding season, blue tit females suffer the attack of nest-dwelling parasites and biting midges in their nests, and they may react in different ways, including behaviourally and physiologically. Although there is no information on the effect of nest-dwelling parasites on HSP-mediated responses in adult wild birds, several studies suggest that infections by blood and nest-dwelling parasites are environmental stimuli triggering stress responses. Moreover, to our knowledge, there is an evidence of the potential interaction of different parasites on HSP60 responses (Merino et al. 1998a); however, this result should be interpreted cautiously because only nestlings from one nest were infected by both nest-dwelling parasites and blood parasites.

We found that nest-dwelling parasites affected the level of HSP60 in blue tit females. Our results suggest that females breeding in non-fumigated nests increased HSP60 levels during the season more than those breeding in fumigated nests. Although the direct mechanisms mediating avian stress responses to biting arthropods are unknown, 
the increase in change in HSP60 level in females from nonfumigated nests could be interpreted as a host mechanism to reduce the adverse effects of parasitic attacks. Host immune systems may respond to blood-sucking attacks (Lehane 2005), and HSPs may play an essential role in regulating immunological responses, as shown in other parasitic infections (Hisaeda and Himeno 1997; Sørensen et al. 2003). Moreover, substances contained in insect saliva, such as anticoagulants, may alter host cellular homeostasis (Urata et al. 2003), and HSPs may limit effects of these injuries. Thus, a decrease in nest-dwelling parasites by fumigation may allow females to reduce HSP60 levels during the season. Additionally, the effects of fumigation on nest-dwelling parasite load could affect the change in HSP60 level indirectly. Females could increase their parental effort to try to reduce the costs of nest-dwelling parasite infections on nestlings (Johnson and Albrecht 1993; Christe et al. 1996; Merino et al. 1998b; Bouslama et al. 2002; Tripet et al. 2002; Tomás et al. 2008b), and physical activity may increase the level of HSP60 in female birds (Merino et al. 2006; Moreno et al. 2008). The potential effect of nest-dwelling parasites on parental effort is supported by the fact that nestling survival and nestling mass did not differ between experimental groups, despite that fumigation potentially favours nestling development through its effect on the abundance of nest-dwelling parasites (see Johnson and Albrecht 1993). However, female provisioning rate did not differ among experimental groups, and provisioning rate and change in HSP60 levels were not significantly associated.

The change in HSP60 level in adult females was positively correlated with the abundance of biting midges. This result could be explained at least by two possibilities. First, biting midges may prefer to feed on more stressed birds. Although plausible, this is poorly supported because birds that were more intensively infected by blood parasites, and presumably more stressed (Tomás et al. 2005; del Cerro et al. 2010), showed lower abundances of biting flies (Darbro et al. 2007; Tomás et al. 2008b). Second, biting midges could induce an HSP60-mediated response in blue tit females. Despite the lack of knowledge on the effects of biting flies on wild birds, studies on nestlings reveal that biting midges and other flying blood-sucking insects may reduce fitness (Hunter et al. 1997; Smith et al. 1998; Tomás et al. 2008b; Martínez-de la Puente et al. 2010a). Biting midges attack not only nestlings but also females in nests (Griffing et al. 2007; Tomás et al. 2008a; Ligon et al. 2009), potentially causing anaemia (Smith et al. 1998), and HSPs could play a role regulating protein synthesis (Anand and Pal 2002). Furthermore, birds suffering from a higher number of biting midge attacks may increase their exposure to pathogens, other parasites and toxins, or allergens potentially contained in insect saliva (Lehane 2005). This is especially important in the case of biting midges acting as vectors of Haemoproteus spp. parasites (Fallis and Wood 1957; Mullens et al. 2006). Due to all these potential effects, the importance of biting flies as inducers of physiological stress could be even higher than that of nest-dwelling parasites. This is partly supported by the significant association between the abundance of biting midges and the change in HSP60 level, while there were not significant associations for other nest-dwelling parasites. Finally, the possibility that HSPs could negatively affect biting arthropods, as is the case for some immunoglobulins (see Tschirren et al. 2007; Owen et al. 2010), seems unlike because contrary to immunoglobulins, HSPs are intracellular proteins involve in defensive mechanism to maintain cellular homeostasis in the presence of stress.

Contrary to our predictions, we did not find any significant effect of medication against blood parasites on the change in HSPs level. According to previous studies, primaquine reduces the intensity of infection by Haemoproteus spp. in female birds in this population (Merino et al. 2000, 2004; Tomás et al. 2005; Martínez-de la Puente et al. 2010b), and the infection by Haemoproteus spp. affects the level of HSP60 in adult blue tits (Tomás et al. 2005; del Cerro et al. 2010). In the present study, although medication reduced the infection by Haemoproteus spp., the effect of this treatment was weaker than expected according to previous studies where significant differences in final intensity of infection were observed between medicated and non-medicated females (i.e. Merino et al. 2000). Differences between studies may be due to inter-annual variations of environmental factors affecting host immune status, including vegetation characteristics around the nest, potentially affecting the abundance of insects (feeding resources) and vector prevalence (Hoi-Leitner et al. 2001; Arriero 2009). The absence of significant differences may partly explain the absence of a significant effect of both, medication treatment and a joint effect of the both treatments on change in HSP60 level. In addition, although differences did not reach significance $(p>0.3)$, we found greater changes in HSP60 level in medicated as compared with control females breeding in fumigated nests (see Fig. 2). It is possible that medication treatment could have adverse effects on birds. However, previous studies on wild birds did not support this possibility because antimalarial drugs reduce the level of stress response (Tomás et al. 2005) and improve reproductive success (Merino et al. 2000; Marzal et al. 2005; Knowles et al. 2010), general body condition (Merino et al. 2000) and survival probability (Martínez-de la Puente et al. 2010b). Alternatively, because medication may increase the abundance of total biting midges or the abundance of a particular species of biting midges in avian nests (see Tomás et al. 2008b; Martínez-de la Puente et al. 2009), it could be possible that medicated 
females increased the HSP60 level as a result of biting midge attacks.

In conclusion, our results support experimentally, to our knowledge, for the first time, the impact of nest-dwelling parasites on stress responses mediated by HSPs of adult females attending nestlings. Also, these results provide an evidence of the potential role of biting midges inducing physiological costs in wild breeding blue tit females. More studies are necessary to investigate in depth the relative importance of several kinds of nest parasites, including both nest-dwelling parasites and biting flies, and endoparasites affecting the physiological status of breeding birds.

Acknowledgements This study was funded by different projects CGL2006-14129-C02-01, CGL2007-61251 and CGL2009-09439 from Ministerio de Educación y Ciencia. The Junta de Castilla y León authorised the ringing and handling of birds. We thank Javier Donés (Director of "Montes de Valsaín") for permission to work in the study area. The authors thank Sonia Aracil for their invaluable help in the lab. J.M.-P. is supported by a postdoctoral grant from Universidad de Las Palmas de Gran Canaria; J. Morales and G. Tomás are supported by Juan de la Cierva fellowships and E. Lobato by a Postdoctoral contract (Ministerio de Ciencia e Innovación). A.V. Bordería kindly supplied the Petri dishes. This study is a contribution to the research developed at "El Ventorrillo" field station. Three anonymous referees considerably improved a previous version of the manuscript with their constructive comments.

\section{References}

Anand S, Pal JK (2002) The haem-regulated eukaryotic initiation factor 2 alpha kinase: a molecular indicator of lead-toxicity anaemia in rabbits. Biotechnol Appl Biochem 36:57-62

Arriero E (2009) Rearing environment effects on immune defence in blue tit Cyanistes caeruleus nestlings. Oecologia 159:697-704

Arriero E, Moreno J, Merino S, Martínez J (2008) Habitat effects on physiological stress response in nestling blue tits are mediated through parasitism. Physiol Biochem Zool 81:195-203

Atkinson CT, van Riper IIIC (1991) Pathogenicity and epizootiology of avian haematozoa: Plasmodium, Leucocytozoan, and Haemoproteus. In: Loye JE, Zuk M (eds) Bird-parasite interactions: ecology, evolution and behaviour. Oxford Univ Press, Oxford, pp 19-48

Bouslama Z, Lambrechts MM, Ziane N, Djenidi R, Chabi Y (2002) The effect of nest ectoparasites on parental provisioning in a north-African population of the blue tit Parus caeruleus. Ibis 144:E73-E78

Buchanan KL (2000) Stress and the evolution of condition-dependent signals. Trends Ecol Evol 15:156-160

Burkett-Cadena ND, Ligon RA, Liu M, Hassan HK, Hill GE, Eubanks MD, Unnasch TR (2010) Vector-host interactions in avian nests: do mosquitoes prefer nestlings over adults? Am J Trop Med Hyg 83:395-399

Christe P, Richner H, Oppliger A (1996) Begging, food provisioning, and nestling competition in great tit broods infested with ectoparasites. Behav Ecol 7:127-131

Darbro JM, Dhondt AA, Vermeylen FM, Harrington LC (2007) Mycoplasma gallisepticum infection in house finches (Carpodacus mexicanus) affects mosquito blood feeding patterns. Am J Trop Med Hyg 77:488-494

del Cerro S, Merino S, Martínez-de la Puente J, Lobato E, Ruiz-deCastañeda R, Rivero-de-Aguilar J, Martínez J, Morales J, Tomás
G, Moreno J (2010) Carotenoid-based plumage colouration is associated with blood parasite richness and stress protein levels in blue tits (Cyanistes caeruleus). Oecologia 162:825-835

de Lope F, Møller AP (1993) Effects of ectoparasites on reproduction of their swallow hosts: a cost of being multi-brooded. Oikos 67:557-562

de Lope F, González G, Pérez JJ, Møller AP (1993) Increased detrimental effects of ectoparasites on their bird hosts during adverse environmental condition. Oecologia 95:234-240

Fallis AM, Wood DM (1957) Biting midges (Diptera: Ceratopogonidae) as intermediate hosts for Haemoproteus in ducks. Can J Zool 35:425-435

Feder ME, Hofmann GE (1999) Heat-shock proteins, molecular chaperones, and the stress response: evolutionary and ecological physiology. Annu Rev Physiol 61:243-282

Fitze PS, Tschirren B, Richner H (2004) Life history and fitness consequences of ectoparasites. J Anim Ecol 73:216-226

Griffing SM, Kilpatrick AM, Clark L, Marra PP (2007) Mosquito landing rates on nesting American robins (Turdus migratorius). Vector-Borne Zoonot 7:437-443

Hisaeda H, Himeno K (1997) The role of host-derived heat-shock protein in immunity against Toxoplasma gondii infection. Parasitol Today 13:465-468

Hoi-Leitner M, Romero-Pujante M, Hoi H, Pavlova A (2001) Food availability and immune capacity in serin (Serinus serinus) nestlings. Behav Ecol Sociobiol 49:333-339

Hunter DB, Rohner C, Currie DC (1997) Mortality in fledgling great horned owls from black fly hematophaga and leucocytozoonosis. J Wildl Dis 33:486-491

Johnson LS, Albrecht DJ (1993) Effects of haematophagous ectoparasites on nestling house wrens, Troglodytes aedon: who pays the cost of parasitism? Oikos 66:255-262

Kettle DS (1995) Medical and veterinary entomology, 2nd edn. CAB International, Wallingford

Knowles SC, Palinauskas V, Sheldon BC (2010) Chronic malaria infections increase family inequalities and reduce parental fitness: experimental evidence from a wild bird population. J Evol Biol 23:557-569

Lehane M (2005) The biology of blood-sucking in insects, 2nd edn. Cambridge University Press, Cambridge

Ligon RA, Burkett-Cadena ND, Liu M, Hill GE, Hassan KH, Unnasch TR (2009) Assessing mosquito feeding patterns on nestling and brooding adult birds using microsatellite markers. Am J Trop Med Hyg 81:534-537

Lobato E, Merino S, Moreno J, Morales J, Tomás G, Martínez-de la Puente J, Osorno JL, Kuchar A, Möstl E (2008) Corticosterone metabolites in blue tit and pied flycatcher droppings: effects of brood size, ectoparasites and temperature. Horm Behav 53:295-305

López-Antuñano FJ (1999) Is primaquine useful and safe as a true exo-erythrocytic merontocidal, hypnozoitocidal and gametocidal antimalarial drug? Salud Pública Méx 41:410-419

Martínez J, Pérez Serrano J, Bernardina WE, Rodríguez-Caabeiro F (1999) Influence of parasitization by Trichinella spiralis on the levels of heat shock proteins in rat liver and muscle. Parasitology 118:201-209

Martínez J, Martínez-de la Puente J, Herrero J, del Cerro S, Lobato E, Rivero-de Aguilar J, Vásquez RA, Merino S (2009) A restriction site to differentiate Plasmodium and Haemoproteus infections in birds: on the inefficiency of general primers for detection of mixed infections. Parasitology 136:713-722

Martínez-de la Puente J, Merino S, Tomás G, Moreno J, Morales J, Lobato E, Talavera S, Sarto I, Monteys V (2009) Factors affecting Culicoides species composition and abundance in avian nests. Parasitology 136:1033-1041

Martínez-de la Puente J, Merino S, Lobato E, Rivero-de Aguilar J, del Cerro, S, Ruiz-de-Castañeda R, Moreno J (2010a) Nest-climatic 
factors affect the abundance of biting flies and their effects on nestling condition. Acta Oecol, in press. doi:10.1016/j. actao.2010.07.008.

Martínez-de la Puente J, Merino S, Tomás G, Moreno J, Morales J, Lobato E, García-Fraile S, Belda EJ (2010b) The blood parasite Haemoproteus reduces survival in a wild bird: a medication experiment. Biol Lett 6:663-665

Martínez-Padilla J, Martínez J, Dávila JA, Merino S, Moreno J, Millán J (2004) Within-brood size differences, sex and parasites determine blood stress protein levels in Eurasian kestrel nestlings. Funct Ecol 18:426-434

Marzal A, de Lope F, Navarro C, Møller AP (2005) Malarial parasites decrease reproductive success: an experimental study in a passerine bird. Oecologia 142:541-545

Merino S, Potti J (1995) Mites and blowflies decrease growth and survival in nestling pied flycatchers. Oikos 73:95-103

Merino S, Martínez J, Barbosa A, Møller AP, de Lope F, Pérez J, Rodríguez-Caabeiro F (1998a) Increase in a heat-shock protein from blood cells in response of nestling house martins (Delichon urbica) to parasitism: an experimental approach. Oecologia 116:343-347

Merino S, Moreno J, Potti J, de León A, Rodríguez R (1998b) Nest ectoparasites and maternal effort in pied flycatchers. Proceedings of the 1st Meeting of the European Ornithological Union. Biol Conserv Fauna 102:200-205

Merino S, Moreno J, Sanz JJ, Arriero E (2000) Are avian blood parasites pathogenic in the wild? A medication experiment in blue tits. Proc Biol Sci 267:2507-2510

Merino S, Martínez J, Møller AP, Barbosa A, de Lope F, RodríguezCaabeiro F (2002) Blood stress protein levels in relation to sex and parasitism of barn swallows (Hirundo rustica). Ecoscience 9:300-305

Merino S, Tomás G, Moreno J, Sanz JJ, Arriero E, Folgueira C (2004) Changes in Haemoproteus sex ratios: fertility insurance or differential sex lifespan? Proc Biol Sci 271:1605-1609

Merino S, Moreno J, Tomás G, Martínez J, Morales J, Martínez-de la Puente J, Osorno JL (2006) Effects of parental effort on blood stress protein HSP60 and immunoglobulins in female blue tits: a brood size manipulation experiment. J Anim Ecol 75:1147-1153

Møller AP (1997) Parasitism and the evolution of host life history. In: Clayton DH, Moore J (eds) Host-parasite evolution: general principles and avian models. Oxford University Press, Oxford, pp 105-127

Moreno J, Martínez J, Corral C, Lobato E, Merino S, Morales J, Martínez-de la Puente J, Tomás G (2008) Nest construction rate and stress in female pied flycatchers Ficedula hypoleuca. Acta Ornithol 43:57-64
Mullens BA, Cardona CJ, McClellan L, Szijj CE, Owen JP (2006) Culicoides bottimeri as a vector of Haemoproteus lophortyx to quail in California, USA. Vet Parasitol 140:35-43

Owen JP, Nelson AC, Clayton DH (2010) Ecological immunology of bird-ectoparasite systems. Trends Parasitol 26:530-539

Richner H, Tripet F (1999) Ectoparasitism and the trade-off between current and future reproduction. Oikos 86:535-538

Rinehart JP, Denlinger DL, Rivers DB (2002) Upregulation of transcripts encoding select heat shock proteins in the flesh fly Sarcophaga crassipalpis in response to venom from the ectoparasitoid wasp Nasonia vitripennis. J Invertebr Pathol 79:62-63

Smith RN, Cain SL, Anderson SH, Dunk JR, Williams S (1998) Blackfly-induced mortality of nestling red-tailed hawks. Auk 115:368-375

Sørensen JG, Kristensen TN, Loeschcke V (2003) The evolutionary and ecological role of heat shock proteins. Ecol Lett 6:1025-1037

Tomás G, Martínez J, Merino S (2004) Collection and analysis of blood samples to detect stress proteins in wild birds. J Field Ornithol 75:281-287

Tomás G, Merino S, Martínez J, Moreno J, Sanz JJ (2005) Stress protein levels and blood parasite infection in blue tits (Parus caeruleus): a medication field experiment. Ann Zool Fenn 42:45-56

Tomás G, Merino S, Moreno J, Morales J (2007) Consequences of nest reuse for parasite burden and female health and condition in blue tits, Cyanistes caeruleus. Anim Behav 73:805-814

Tomás G, Merino S, Martínez-de la Puente J, Moreno J, Morales J, Lobato E (2008a) A simple trapping method to estimate abundances of blood-sucking flying insects in avian nests. Anim Behav 75:723-729

Tomás G, Merino S, Martínez-de la Puente J, Moreno J, Morales J, Lobato E (2008b) Determinants of abundance and effects of blood-sucking flying insects in the nest of a hole-nesting bird. Oecologia 156:305-312

Tripet F, Glaser M, Richner H (2002) Behavioural responses to ectoparasites: time-budget adjustments and what matters to blue tits Parus caeruleus infested by fleas. Ibis 144:461-469

Tschirren B, Bischoff LL, Saladin V, Richner H (2007) Host condition and host immunity affect parasite fitness in a bird-ectoparasite system. Funct Ecol 21:372-378

Urata J, Shojo H, Kaneko Y (2003) Inhibition mechanisms of hematophagous invertebrate compounds acting on the host blood coagulation and platelet aggregation pathways. Biochimie 85:493-500

Whittingham MJ, Stephens PA, Bradbury RB, Freckleton RP (2006) Why do we still use stepwise modelling in ecology and behaviour? J Anim Ecol 75:1182-1189

WHO (2001) The use of antimalarial drugs: report of an informal consultation. World Health Organization, Geneva 